said that if the engineer is to be an important figure in public affairs he must acquire a broader technique than that which he usually possesses, and must inform himself concerning a wide range of subjects of which ordinarily he knows little. Furthermore, he must acquire a wide knowledge of economic history, and be able to trace the effect of economic changes over long periods of time. The engineer who aspires to solve modern economic problems must expect to do an unusual amount of studying before he can replace older economic theories with others which are suited to our day and methods. Perhaps no field of knowledge presents such a bewildering array of theories which purport to tie together groups of phenomena more or less vaguely connected. If the engineer can apply his analytical methods to those vague relations and develop the basic facts through his more intimate knowledge of industry, he could indeed perform a most useful service. In so doing, however, the engineer should avoid dogmatic statements. In his own field he may be quite dogmatic at times but in the field of general economics he must be more careful. This is particularly true of mathematical deductions as to future trends. Economic variables frequently change with new discoveries and changed conditions and it is very unwise therefore to interpolate any curve involving economic variables.

\section{Tropical Land Tenure}

IN a valuable survey entitled "Studies in Tropical Land Tenure" (Government Printing Office, Port-ofSpain, Trinidad. Price $2 s$.), Dr. H. Martin Leake shows that the most striking feature of the systems of land tenure found in the different tropical components of the British Empire is their extraordinary diversity despite the fact that, in all cases, their wealth is primarily and dominantly agricultural. A land tenure system, he points out, must be judged by two standards: (1) an economic standard-its capacity to supply that export trade which is an essential to progress, and (2) a sociological standardits capacity to afford opportunities to the component sections of the community to develop their innate capacities. Only in the last generation has the welfare and progress of the indigenous population come to be accepted as the primary consideration to which all others must give precedence. The practical policy by which it is hoped to attain this desideratum is the maintenance of the indigenous system of administration so far as it is acceptable as a moral code. The evolution from an indigenous land system to a peasant system producing for export necessitates the aggregation of the small farming units, so that they become subject to a unified control as regards production for export. Dr. Leake recommends a system of vertical co-operation between the peasant, the productive organisation and the State such as has been successfully adopted in the Gezira district of the Sudan and among the sugar growers of Fiji.

\section{First Appearance of Snapdragon Disease in England}

THe appearance of a new plant disease in England is rightly treated as a serious matter, and the unex- pected appearance of the rust fungus, Puccinia Antirrhini, on the cultivated snapdragon in several districts in the south of England this summer, will be viewed with alarm by many growers. Although the antirrhinum is a European plant, hitherto no rust fungus has been recorded on it in that Continent, the British Isles included, but curiously enough the disease has become a menace in the United States, where the snapdragon was introduced from Europe a long time ago. The same rust also occurs in Canada and Bermuda, but has not as yet been recorded elsewhere. The source of the outbreaks in England this year are unknown, but the hot weather has probably favoured their development. The disease is easily recognised by the dark brown or snuffcoloured pustules on the leaves and stems and all affected plants (and healthy ones in proximity to them) should be immediately burnt if the pest is to be prevented from obtaining a permanent foothold. In the event of an outbreak of rust having occurred, no antirrhinums should be allowed to carry over the winter, or there will be a danger of a recurrence of the trouble in the following summer. The disease is not thought to be seed-borne.

\section{Range of Variation in the Leopard}

THose interested in the study of variation, in regard to the size and coloration displayed by animals having a wide geographical distribution, will be glad to learn that a pair of Indian leopards, from Hyderabad, has just been added to the collection in the Gardens of the Zoological Society of London. The range of the leopard is greater than that of any other of the larger carnivores, since it inhabits the whole of Asia, and is found almost throughout Africa; and everywhere it shows a tendency to split up into groups, such as, were they isolated for a sufficiently long period, would give rise to distinct species. The Indian leopard, for example, may range in length between five to so much as eight feet; while the tail may measure from a half to threequarters of the length of the body. In the Persian leopard the length of the hair, and the bushiness of the tail approaches the snow-leopard, a nearly related species. The Manchurian leopard is still more distinct. The African leopard shows an even greater range of variation in these particulars, and we have yet to find an explanation of the curious fact that individuals from East Africa have large 'rosettes' like those of Persian and Indian leopards, while those from West Africa are characterised by the small size and great number of their spots which nowhere form the rings or 'rosettes' of the typical leopard. The same is true of the Albany district of South Africa. We have this much as a basis for further study; that such as are found in open country have a light golden-tawny ground colour, while those from damp, tropical forests are darker. The smallest of all the tribe are leopards from Somaliland, where, it may be noted, lions are also smaller. They have, indeed, been described as pigmy-leopards. That these differences are associated in some subtle way with the nature of their haunts and habits seems a 